\title{
O trabalho com gêneros textuais em um curso de Pedagogia: uma proposta de produção editorial para o letramento profissional
}

\author{
Cláudia de Jesus Abreu Feitoza ${ }^{1}$ \\ Milena Moretto ${ }^{2}$
}

\section{Resumo}

Em nossas experiências como professoras do ensino superior, temos observado que são muitas as dificuldades de escrita de alunos ingressantes e, inclusive, concluintes nos cursos de Pedagogia. Diante disso, neste texto, temos como objetivo discutir acerca das contribuições de uma experiência prática de formação inicial, no que diz respeito à aprendizagem de leitura e escrita de gêneros textuais que, embora não pertençam à esfera acadêmica, serão objeto de ensino dos pedagogos em atuação nos diferentes segmentos de ensino e anos em que irão atuar. Fundamentando-nos na perspectiva enunciativo-discursiva e nas considerações dos Novos Estudos do Letramento, desenvolvemos um trabalho de produção editorial que, diante de nossas análises, contribuiu para o letramento profissional dos estudantes.

Palavras-chave: Gêneros textuais; Letramento Profissional; Formação inicial.

The work with textual genres in a Pedagogy course: a proposal of editorial production for professional literacy

\begin{abstract}
In our experiences as teachers of higher education, we have observed that there are many difficulties in writing entry and even graduating students in Pedagogy courses. Given this, in this text, we aim to discuss about the contributions of a practical experience of initial formation with regard to learning to read and write textual genres that - although not belonging to the academic sphere - will be the object of teaching by the pedagogues in action. in the different segments of education and years in which they will operate. Based on the enunciative-discursive perspective and considerations of New Literacy Studies, we developed a work of editorial production that, in view of our analyzes, contributed to the professional literacy of students.
\end{abstract}

Keywords: Textual genres; Professional Literacy; Initial formation.

\section{Considerações iniciais}

Diversas são as possibilidades de atuação do pedagogo, que pode seguir, dentre muitas áreas profissionais, a carreira como gestor educacional, professor de educação infantil, ensino fundamental I, dentre outras. O professor formado em Pedagogia, ao seguir a carreira docente, sobretudo na atuação no ensino fundamental tem, atualmente, como um dos grandes desafios lecionar disciplinas específicas tais como História, Geografia, Língua Portuguesa e Ciências; ao

\footnotetext{
${ }^{1}$ Universidade São Francisco, Itatiba e endereço eletrônico: clauabreu_20@hotmail.com

2 Universidade São Francisco, Itatiba e endereço eletrônico: milena.moretto@yahoo.com.br
} 


\section{HSE HORIZON TES}

contrário de outras épocas em que ele deveria basicamente formar alunos alfabetizados, proficientes em língua portuguesa e matemática. Ocorre que ante uma organização curricular que cobra conteúdos cada vez mais específicos, os professores do ensino fundamental I precisam aprender a ensinar tais conteúdos que, em muitos casos, foram aprendidos de forma superficial ou incompatível com a prática, em sua formação inicial.

No âmbito do ensino de Língua Portuguesa, os currículos a serem adotados nas escolas, tanto públicas quanto privadas, são organizados a partir de diretrizes nacionais, como Parâmetros Curriculares Nacionais (PCN) e, atualmente, a Base Nacional Comum Curricular (BNCC). Nesses documentos, a proposta de trabalho de leitura e escrita centra-se em uma abordagem discursiva, que toma o texto como objeto de ensino e o ensino de Língua Portuguesa parte da ideia de uso social da língua por meio dos gêneros de textos, em diferentes situações de uso (BRASIL, PCN, 1999; BNCC, 2018).

Nesse sentido, compreender a perspectiva de trabalho com gêneros textuais orais e escritos - necessidade antes limitada aos professores de Língua Portuguesa - passa a ser uma demanda também dos professores atuantes no ensino fundamental. Mas, mais do que isso, é necessário ter domínio prático sobre os gêneros textuais a serem ensinados. A questão central deste estudo refere-se ao fato de que, na atuação profissional, muitos professores se veem destinados a ensinar os alunos a escreverem gêneros textuais que, em muitos casos, os próprios professores não têm o pleno domínio.

Esse requisito levou-nos a elaborar um projeto interdisciplinar a ser desenvolvido em um curso de formação inicial de Pedagogia, cujo objetivo foi proporcionar aos estudantes do 5.o semestre da disciplina de Fundamentos e Metodologias do Ensino de Língua Portuguesa uma experiência prática de leitura e escrita de gêneros textuais de diversas esferas de circulação, os quais se tornariam objeto de ensino desses estudantes como futuros professores.

Assim, o objetivo deste texto é discutir acerca das contribuições de uma experiência prática de formação inicial, no que diz respeito à aprendizagem de leitura e escrita de gêneros textuais que - embora não pertençam à esfera acadêmica - serão objeto de ensino dos pedagogos em atuação, em diferentes segmentos de ensino e anos em que irão atuar.

Nesse sentido, foi realizada uma proposta de trabalho em que os alunos do 5.0 
semestre do curso de Pedagogia deveriam apresentar - como trabalho final de avaliação da disciplina Fundamentos e Metodologias do Ensino de Língua Portuguesa - uma revista temática que contemplasse diferentes gêneros textuais produzidos por eles. O propósito desse trabalho era justamente levar os alunos a lerem e produzirem gêneros de textos que, como futuros professores, eles passariam a ensinar.

Para apresentar e discutir a respeito dessa experiência, bem como acerca das contribuições do trabalho para alunos de Pedagogia em formação, organizamos este artigo que está estruturado em cinco seções, além da introdução. Inicialmente, discutimos sobre os multiletramentos em um contexto de formação: sobre o aprender para ensinar. Em seguida, como um trabalho com gêneros textuais na formação inicial pode possibilitar o letramento profissional. Após, apresentamos os procedimentos metodológicos de produção dos dados da pesquisa para, posteriormente, discutir sobre como o trabalho realizado contribuiu para que os alunos se apropriassem e produzissem gêneros pertencentes a diferentes esferas da atividade, uma vez que estes gêneros são demasiadamente importantes para a constituição do futuro professor de ensino fundamental I e para sua atuação profissional.

\section{Multiletramentos e letramento de professores iniciantes: aprender para poder ensinar}

Desde a década de 90, a concepção de letramento no Brasil vem sendo associada às práticas de leitura e escrita, além de frequentemente vinculada ao ensino de língua portuguesa. Autores dos Novos Estudos do Letramento como Kleiman (1995), por exemplo, defendem que o letramento está associado a práticas sociais de uso da linguagem. E, tais práticas pressupõem o uso de diferentes gêneros textuais a serem utilizados nas diversas esferas da atividade humana.

A esse respeito, Street (2014) e Rojo (2009) explicam que há diversos tipos de letramentos e - considerando a natureza social e cultural da linguagem nas práticas de leitura e escrita - não se pode falar em letramento ou letramentos, mas em letramentos múltiplos.

O conceito de letramentos múltiplos é ainda um conceito complexo e muitas vezes ambíguo, pois envolve, além da questão da multissemiose ou multimodalidade das mídias digitais que lhe deu origem, pelo menos duas

Periódico Horizontes - USF - Itatiba, SP - Brasil - e020010 
facetas: a multiplicidade de práticas de letramento que circulam em diferentes esferas da sociedade e a multiculturalidade, isto é, o fato de que diferentes culturas locais vivem essas práticas de maneira diferente (ROJO, 2009, p.108109).

Segundo Rojo e Barbosa (2015, p. 53), as práticas sociais situadas estão relacionadas ao domínio de determinados gêneros discursivos, de modo que "os gêneros discursivos integram as práticas sociais e são por elas gerados e formatados". Nessa mesma linha, Street (2014) enfatiza que os letramentos múltiplos surgem diante da diversidade e complexidade de práticas culturais e sociais de leitura e escrita que se fazem presentes na sociedade atual. Essa complexidade está associada ao fato de que, segundo Bakhtin (2010), os gêneros discursivos são eventos constituídos na/pela sociedade, o que os torna dinâmicos, flexíveis e em número praticamente incontável.

Embora a maior parte de estudos sobre letramento esteja centrada em aspectos didáticos e metodológicos de alfabetização e ensino de língua portuguesa, Street (2014) traz contribuições sobre os letramentos múltiplos. Para isso, ele diferencia o letramento autônomo - relacionado mais estritamente às habilidades individuais do sujeito, do ideológico - que propõe uma prática social implícita nos princípios socialmente construídos, pois "[...] os modos pelos quais as pessoas usam a leitura e a escrita são atrelados a concepções de conhecimento, identidade e modos de ser e estar, nas práticas sociais ou contextos particulares" (COLAÇO, 2012, p.2).

Street (2014) esclarece que essa multiplicidade de letramentos mantém relação com a diversidade de papéis sociais que o sujeito representa em diferentes contextos sócio-históricos de uso da linguagem. Isso porque, em cada situação de comunicação recorremos a práticas textuais que se dão por meio de gêneros discursivos diversos, para os quais mobilizamos diferentes papéis sociais. A esse respeito, Lemke (2010 apud ROJO; BARBOSA, 2015, p. 53) define que:

Um letramento é sempre um letramento em algum gênero e deve ser definido com respeito aos sistemas sígnicos empregados, às tecnologias materiais usadas e aos contextos sociais de produção, circulação e uso de um gênero particular. Podemos ser letrados em um gênero de relato de pesquisa científica ou em um gênero de apresentação de negócios. Em cada caso, as habilidades de letramento específicas e as comunidades de comunicação relevantes são muito diferentes. 
Assim, os letramentos dos sujeitos serão dependentes desses contextos, em que as relações de poder desempenham papel predominante. Embora o modelo ideológico envolva o autônomo, é importante destacar que ele é mais abrangente, uma vez que as práticas de letramento são determinadas por características sócio-históricas, dependentes do período e do local em que ocorrem, fazendo com que o indivíduo organize suas práticas de linguagem de acordo com a esfera de atividade ou de circulação dos gêneros do discurso que mobiliza.

Bakhtin (2010) define o conceito de esfera de atividade ou de circulação de discursos como o domínio de produção discursiva ou atividade humana em que os gêneros discursivos circulam. Para ele, todas as esferas da atividade humana, por mais variadas que sejam, estão sempre relacionadas com a utilização da língua (BAKHTIN, 2010). Assim, em nossas esferas de atividade - familiar, profissional, escolar, acadêmica, jornalística, religiosa, artística, publicitária, dentre outras - assumimos diferentes posições sociais e, ora atuamos como interlocutores, ora como produtores de discursos. Nesse sentido, o autor ressalta que cada campo de uso da língua elabora seus tipos relativamente estáveis de enunciados, o que ele denomina gêneros do discurso. Esses gêneros refletem sempre as condições específicas dessa ou daquela esfera e seus três elementos: o conteúdo temático, a construção composicional e o estilo. Eles estão indissoluvelmente ligados ao todo do enunciado e são determinados por esses campos da comunicação.

Essas esferas de atividade/circulação de discursos interpenetram-se na vida das pessoas que, para as diferentes práticas comunicativas de uso da linguagem, recorrem a diferentes gêneros do discurso (ROJO; BARBOSA, 2015). Assim, considerando o caráter múltiplo das práticas letradas pelas quais circulamos, temos, no ensino superior, as práticas de leitura e escrita acadêmicas, as quais integram as situações em que os estudantes terão de ler e produzir textos nessa esfera, como relatório, monografia, resumo, ensaio etc. No entanto, no caso do curso de Pedagogia, os (futuros) professores, além da apropriação de gêneros que circulam no meio acadêmico, precisam se apropriar de gêneros que serão ensinados, uma vez que serão responsáveis pelos múltiplos letramentos dos seus (futuros) alunos.

Perante essa necessidade de ser letrado para as especificidades da docência, temos o que podemos chamar de letramento profissional. Da mesma maneira que um publicitário 


\section{USFF нов IZоNтеS}

precisa ter pleno domínio de panfletos, folhetos, anúncios e peças publicitárias - uma vez que deverá saber produzi-los - o futuro professor vê-se diante de uma multiplicidade de letramentos ainda mais complexos. Por exemplo, mesmo que não seja jornalista, deverá se apropriar de gêneros discursivos como notícia, reportagem, artigo de opinião dessa esfera e de suas características para poder ensiná-los. Da mesma maneira, a atividade docente exigirá a capacidade de ensinar os alunos a lerem criticamente e/ou produzirem uma propaganda, por exemplo.

É diante dessa complexidade das práticas letradas que abrange a atuação profissional de um professor pedagogo, que discutiremos sobre a importância do letramento profissional durante a formação inicial.

\section{Letramento profissional do futuro pedagogo}

Conforme já discorremos anteriormente, a licenciatura em Pedagogia não deve se limitar à apropriação de textos da esfera acadêmica, mas estende-se também ao domínio de gêneros discursivos que os futuros professores irão ensinar. A essa apropriação de textos que farão parte da profissão, podemos denominar de letramento profissional. De acordo com Costa e Paz (2017, p. 109):

As discussões sobre o uso da linguagem no exercício profissional ou na formação para o trabalho vêm se ampliando de forma considerável nas últimas décadas. Isso porque pesquisadores da área dos Estudos de Letramento têm buscado dar visibilidade a esse domínio discursivo e à relevância que a escrita assume nesses contextos como uma forma de agência.

No caso de professores em geral, é evidente que saber ler e produzir gêneros discursivos como relatórios, planejamentos, planos de aulas - dentre outros inerentes à função docente - não é suficiente para que sejam letrados para a profissão. Mais do que isso - em especial o pedagogo - precisará dominar textos de diferentes gêneros e esferas de atividade humana, haja vista que seus alunos deverão ser letrados a partir das necessidades delas. Para Rojo, 
As esferas ou campos de atividade humana ou de circulação dos discursos - já que toda atividade humana se entretece de discursos - são a instância organizadora da produção, circulação, recepção dos textos/enunciados em gêneros de discurso específicos em nossa sociedade (ROJO, s/d, s/p) ${ }^{3}$.

Schneuwly e Dolz (2004) denominam as esferas de atividade humana de domínios sociais de comunicação, delimitando, dentro de cada categoria, os gêneros pertencentes a cada um deles, além dos tipos textuais predominantes em cada gênero, conforme quadro a seguir.

Quadro 1 - classificação dos gêneros por domínios sociais de comunicação

\begin{tabular}{|c|c|c|}
\hline $\begin{array}{c}\text { Domínios sociais de } \\
\text { comunicação }\end{array}$ & $\begin{array}{l}\text { Aspectos } \\
\text { tipológicos }\end{array}$ & $\begin{array}{c}\text { Exemplos de gêneros } \\
\text { orais e escritos }\end{array}$ \\
\hline Cultura literária e ficcional & Narrar & $\begin{array}{l}\text { - Parábola } \\
\text { - Piada } \\
\text { - História engraçada }\end{array}$ \\
\hline $\begin{array}{l}\text { Documentação e memori- } \\
\text { zação das ações humanas }\end{array}$ & Relatar & $\begin{array}{l}\text { - Diário íntimo } \\
\text { - Depoimento } \\
\text { - Crônica }\end{array}$ \\
\hline $\begin{array}{l}\text { Discussão de problemas } \\
\text { sociais controversos }\end{array}$ & Argumentar & $\begin{array}{l}\text { - Textos de opinião } \\
\text { - Carta do leitor } \\
\text { - Editorial }\end{array}$ \\
\hline $\begin{array}{l}\text { Transmissão e construção } \\
\text { de saberes }\end{array}$ & Expor & $\begin{array}{l}\text { - Artigo enciclopédico } \\
\text { - Entrevista de especialista } \\
\text { - Seminário }\end{array}$ \\
\hline Instruções e prescrições & Descrever ações & $\begin{array}{l}\text { - Receita médica } \\
\text { - Instruções de uso } \\
\text { - Regulamentos }\end{array}$ \\
\hline
\end{tabular}

Fonte: Schneuwly; Dolz (2004, p. 60)

Vale destacar que o domínio de comunicação diz respeito a uma instância de produção discursiva ou de atividade humana, as quais apresentam semelhanças entre si e, de acordo com a intenção comunicativa ou uso da linguagem que fazemos, podem ser agrupadas por áreas e/ou esferas de atividade humana específicas, como atividades cotidianas, área religiosa, área

\footnotetext{
${ }^{3}$ Disponível em Glossário Ceale. Termos de Alfabetização, Leitura e Escrita para Educadores. Universidade Federal de Minas Gerais (UFMG). Disponível em: http://ceale.fae.ufmg.br/app/webroot/glossarioceale/verbetes/esferas-ou-campos-deatividade-humana. Acesso em 30.09.2019.
}

Periódico Horizontes - USF - Itatiba, SP - Brasil - e020010 
jornalística, área literária, área escolar, etc. Cada esfera da atividade humana tem sua linguagem própria, com gêneros textuais bastante específicos. Essas esferas, por sua vez, não são textos nem discursos, mas propiciam o surgimento de discursos (MARCUSCHI, 2010).

O conceito de gêneros de texto, segundo Bakhtin (2010, p. 262), diz respeito ao "conjunto de enunciados relativamente estáveis", isto é, os textos têm formas de organização, temas e linguagem recorrentes que os torna pertencentes a um gênero de texto ou outro. Dessa maneira, compreendemos que não há como o futuro professor pôr-se a ensinar gêneros discursivos sem que ele próprio não os domine minimante em suas características básicas.

Em sua revisão bibliográfica acerca de letramentos profissionais, Costa e Paz (2017) apontaram a necessidade de serem promovidos estudos voltados a esse tema, uma vez que "as atividades de linguagem utilizadas no âmbito profissional assumem espaço importante no estabelecimento de relação e na efetivação do trabalho" (p. 201).

Embora possa parecer desnecessário ensinar, no ensino superior, os gêneros discursivos que supostamente os acadêmicos já integraram em algum momento na educação básica, é indispensável dizer que, enquanto futuro professor, as condições que ele se encontra como aprendiz de determinados gêneros são distintas daquelas quando aprendeu na sua formação escolar. Sobre isso, Costa e Paz (2017, p.201-202) defendem que:

existem muitas possibilidades e maneiras de efetivação de certas práticas de letramentos que podem variar de acordo com tempo, com o espaço, com a cultura etc. Assim sendo, uma mesma prática de letramento pode atender a variadas finalidades, conforme o espaço em que se efetiva, os objetivos dos interlocutores e a sua cultura.

Outro fator preponderante pela escolha de se ensinar gêneros discursivos que os futuros professores irão se colocar a ensinar é em razão das particularidades de suas práticas de letramento profissional serem constituídas por sujeitos situados em um dado tempo, momento, espaço e cultura. Os alunos com os quais irão atuar pertencem a uma geração que está constantemente ligada a recursos tecnológicos e midiáticos. A esse respeito, Kleiman (2014, p. 76) afirma que:

O processo de apropriação de uma tecnologia ou de algum outro recurso midiático - o acesso - depende das estratégias forjadas pelos próprios

Periódico Horizontes - USF - Itatiba, SP - Brasil - e020010 
sujeitos para fazer uso do material. A disponibilidade diz respeito apenas às condições materiais existentes; sem uma construção individual, o recurso disponível é inutilizável.

Nesse sentido, os Novos Estudos do Letramento nos permitem reconhecer que a formação do professor (futuro pedagogo) estará ancorada em práticas sociais de linguagem sob um contexto que tem como recursos materiais as diferentes tecnologias; logo, também faz sentido promover uma formação em que a construção do seu letramento profissional perpasse a realidade com a qual deverá conviver. Assim, entende-se que o letramento profissional do pedagogo permite "o empoderamento dos profissionais" que como professores vão atuar como "agentes de letramento e, consequentemente, de transformação do universo em que desenvolvem as suas atividades laborais" (COSTA; PAZ, 2017, p. 204).

\section{O contexto e a produção dos dados da pesquisa}

Considerando que, conforme já apontamos, o objetivo deste texto é discutir acerca das contribuições de uma experiência prática de formação inicial no que diz respeito à aprendizagem de leitura e escrita de gêneros textuais que - embora não pertençam à esfera acadêmica - serão objeto de ensino dos pedagogos em atuação em diferentes segmentos de ensino e anos em que irão atuar, foi proposta a alunos do 5o semestre do curso de Pedagogia de uma universidade privada da região metropolitana de Campinas a produção de uma revista pedagógica. Para elaborar a revista, os estudantes precisaram escolher um tema de interesse relacionado à área e organizar o suporte a partir da escrita de diversos gêneros textuais que foram estudados previamente em sala de aula: editorial, reportagens, entrevistas, biografias, propagandas, notícias, tiras, artigos de opinião, resenhas entre outros.

Para dar início ao trabalho, os alunos foram divididos em grupos de até cinco. Após eles terem estudado as características de cada gênero textual condizente com o conteúdo temático, a estrutura composicional e o estilo (BAKHTIN, 2010) e terem delimitado o tema de interesse para a construção da revista, houve um movimento interativo intenso em sala de aula, com diálogo e aprendizagem durante o processo de produção.

O resultado dessa prática aconteceu a partir de duas etapas: primeiramente, 


\section{HSE HORIZON TES}

trabalhamos com o ensino de diversos gêneros textuais, em especial da esfera jornalística, como reportagem, notícia, entrevista, artigo de opinião e carta ao leitor. Na segunda etapa, apresentamos como deveria ser o projeto de construção da revista e a função social desses textos para ser apresentado à comunidade acadêmica.

Após estudos de aproximadamente dois meses de diversos gêneros discursivos, apresentamos aos pedagogos as orientações para a produção da revista. Elas estavam divididas em duas partes: na primeira, indicamos o contexto de produção da revista, salientando que, embora se tratasse de um trabalho da disciplina, os alunos deveriam ter em mente que o público-alvo seria os alunos da universidade, sendo o produto voltado ao entretenimento/informação e não com finalidades acadêmicas. Além disso, foram orientados a buscar temas recorrentes em outras revistas da área, bem como pesquisar e identificar estruturas de editoração e organização recorrentes nesses veículos. Para produzir suas próprias revistas, os alunos foram orientados a utilizar programas simples de edição (word), ou outro que tivesse algum domínio. 
Quadro 2 - Orientações sobre gêneros e seções do projeto editorial da revista

1) CONTEÚDO: A revista deverá, obrigatoriamente, conter os seguintes itens:

a) Capa (criar um nome) e seguir o "layout" de uma revista (conforme orientações dadas em sala). A Capa deverá ter a ilustração principal (de acordo com a reportagem de capa) e também as chamadas secundárias, além de preço, código de barras, logomarca da editora etc.

b) Editorial/Carta ao leitor: sobre a revista e sobre o tema principal da capa;

c) Sumário: indicação das páginas e seções ao longo da Revista;

d) Seções Obrigatórias (os títulos das seções devem ser criados, TODOS os textos aqui devem ser de AUTORIA):

- Literária (transformando o gênero canção em outro). Textos literários de autoria: contos, crônicas, poemas etc.

- Informativa: notícias/notas/fatos curiosos e/ou engraçados, acontecidos na universidade ou na região.

- Reportagem da capa: Pesquisar e escrever uma reportagem sobre o tema de interesse/sugerido associado ao estudo das disciplinas do curso/educação. (Ex. importância das práticas esportivas na escola, inclusão, educação socioemocional na escola, importância da educação infantil para o desenvolvimento da criança, trabalho com o lúdico nas atividades de matemática, bullying, ensino de ciências, escolas não-formais etc.).

- Entrevista: preferencialmente feita com uma pessoa que tenha relação ou envolvimento com o tema da reportagem de capa;

- Artigo de opinião: texto de autoria dos alunos que deve estar relacionado ao tema da reportagem de capa e discutir a questão de forma persuasiva e polêmica;

- Coluna Social: Fotos de alunos/eventos, turma da classe etc. (informações pessoais e autorizadas - todas com legenda);

- Biografia: o grupo deverá escolher alguém (pessoa de seu convívio) para fazer uma biografia;

- Resenhas: de Leitura; de Filme; de Games, Séries etc. (Nessa seção devem ser feitos textos de autoria, ou seja, objetos culturais com os quais o aluno realmente tenha tido contato).

- Diversão: nesta seção, podem constar: piadas, desafios, advinhas, tirinhas, charges (não precisam ser de autoria), pensando no tema da reportagem principal da capa

- Propagandas: podem aparecer para "preencher" espaços/lacunas da Revista (não são obrigatórias, anúncios, classificados e propagandas.

Observação: Os alunos têm toda a liberdade para criar seções que não aparecem na lista ou substituir pelas que foram indicadas, desde que se oriente previamente com a professora, que coloca-se à disposição para esclarecer eventuais dúvidas durante as aulas ou por e-mail.

Fonte: Arquivo das pesquisadoras

Nesse quadro, constavam, além das seções da revista, os gêneros discursivos e as esferas de circulação a serem contempladas. Sendo a revista um suporte bastante diversificado, foi possível propor aos alunos uma variedade significativa de gêneros a serem produzidos. Por exemplo, da esfera jornalística: indicamos entrevista, artigo de opinião, reportagem, notícia, editorial; da literária: contos, crônicas, poemas; do entretenimento: piadas, tirinhas, desafios; da esfera publicitária: anúncios, classificados, propagandas.

A proposta demandou apropriação não apenas dos gêneros discursivos, mas também 
permitiu a inserção de uma prática pedagógica no ensino superior do que chamamos de letramento digital. Acerca disso, Kleiman (2014, p. 80) considera que:

No letramento digital, o texto ou hipertexto tem uma organização em que a linguagem verbal, a imagem e o som têm um papel importante na significação, exigindo uma leitura na qual o próprio leitor define quais elementos ler, em qual ordem, seja ele altamente proficiente ou iniciante no processo de aquisição da língua escrita [...].

Na proposta de produção de revista, as ferramentas digitais utilizadas para a digitação e a formatação permitiram aos alunos apropriarem-se não apenas dos recursos de edição, mas também de reconhecer que o tipo de suporte em que os textos foram organizados carecia de certa organização, atendendo, assim, à expectativa do leitor, nesse caso, à comunidade acadêmica e também a outros alunos de Pedagogia. Assim, embora a revista fosse impressa, os textos que a integravam tinham organização própria, obedecendo a uma estrutura do gênero e da diagramação em que eram dispostos os elementos verbais e não verbais.

Posteriormente, os alunos passaram à produção da revista em aulas supervisionadas para orientação, correção e produção dos textos. Ao todo, foram produzidas 10 revistas que tinham os seguintes temas: educação e meio ambiente, brincadeiras atuais e antigas, inclusão, música durante o processo de alfabetização, educação e tecnologia, didática e bullying. Após finalizadas e impressas, as revistas foram apresentadas para a comunidade acadêmica e colocadas em exposição na semana da Pedagogia. A título de exemplificação, selecionamos uma dessas revistas para discutir como os alunos se apropriaram das especificidades do gênero e de que forma essa prática contribuiu para o letramento profissional desses estudantes.

\section{A revista "The nature": indícios da apropriação das especificidades de diversos gêneros textuais e suas contribuições para o letramento profissional}

The nature foi produzida por um grupo de três alunas. A revista teve como tema discutir sobre a importância do respeito pela natureza e preservação do meio ambiente. Já na capa, elas deram destaque ao título, colocaram ano e edição, bem como a data de término da produção da revista. Nela, há também a imagem de um adulto segurando a mão de uma 


\section{USF HоRIZONTES}

criança - tema esse que será defendido por elas nos gêneros que apresentarão: a de que a geração atual precisa preservar o meio para que as futuras gerações possam viver com tranquilidade. A capa apresenta ainda algumas chamadas de textos que o leitor pode encontrar durante a leitura do material: uma resenha do filme "Lorax: em busca da trúfula perdida"; uma notícia sobre Filhotes de Tigres Siberianos, que nasceram no zoológico de Itatiba e uma chamada para uma propaganda de filme. Além disso, as alunas apresentam um código de barras, elemento muito comum nas capas de revistas, caracterizando os periódicos que circulam nas diferentes esferas da atividade humana, como é o caso da esfera jornalística aqui retratada.

Figura 1 - Capa da revista produzida

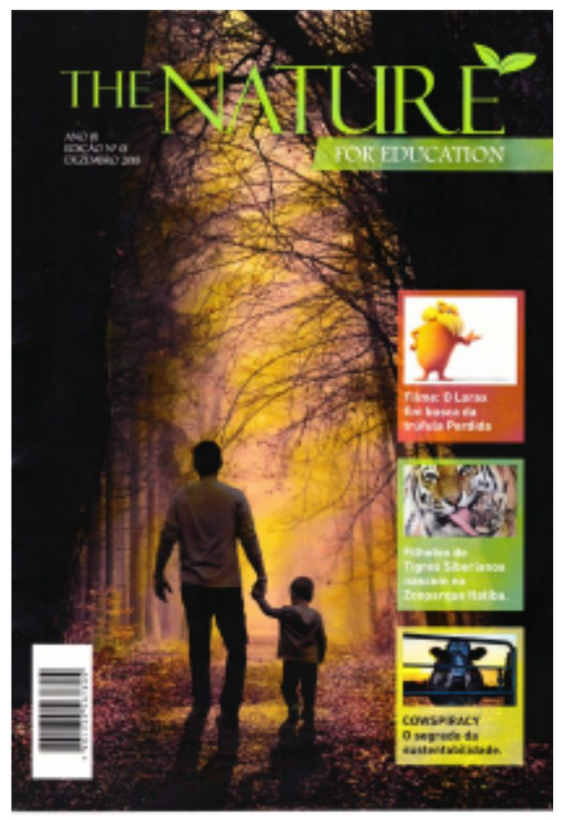

Fonte: arquivo das pesquisadoras

Nas primeiras páginas, as produtoras apresentam um editorial e o sumário da revista. No editorial, buscam uma interlocução com um leitor real, aquele que ultrapassa a mera avaliação do trabalho da disciplina de Fundamentos da Língua Portuguesa, uma vez que os gêneros, nesse caso específico, embora sejam utilizados como objetos de ensino, transcendem essa condição, à medida que as produções circularão para outros espaços que não a sala de aula. Os textos veiculados terão outros interlocutores e outra função social quando a revista for 
colocada em exposição para a comunidade acadêmica.

Figura 2 - O editorial e o sumário da revista

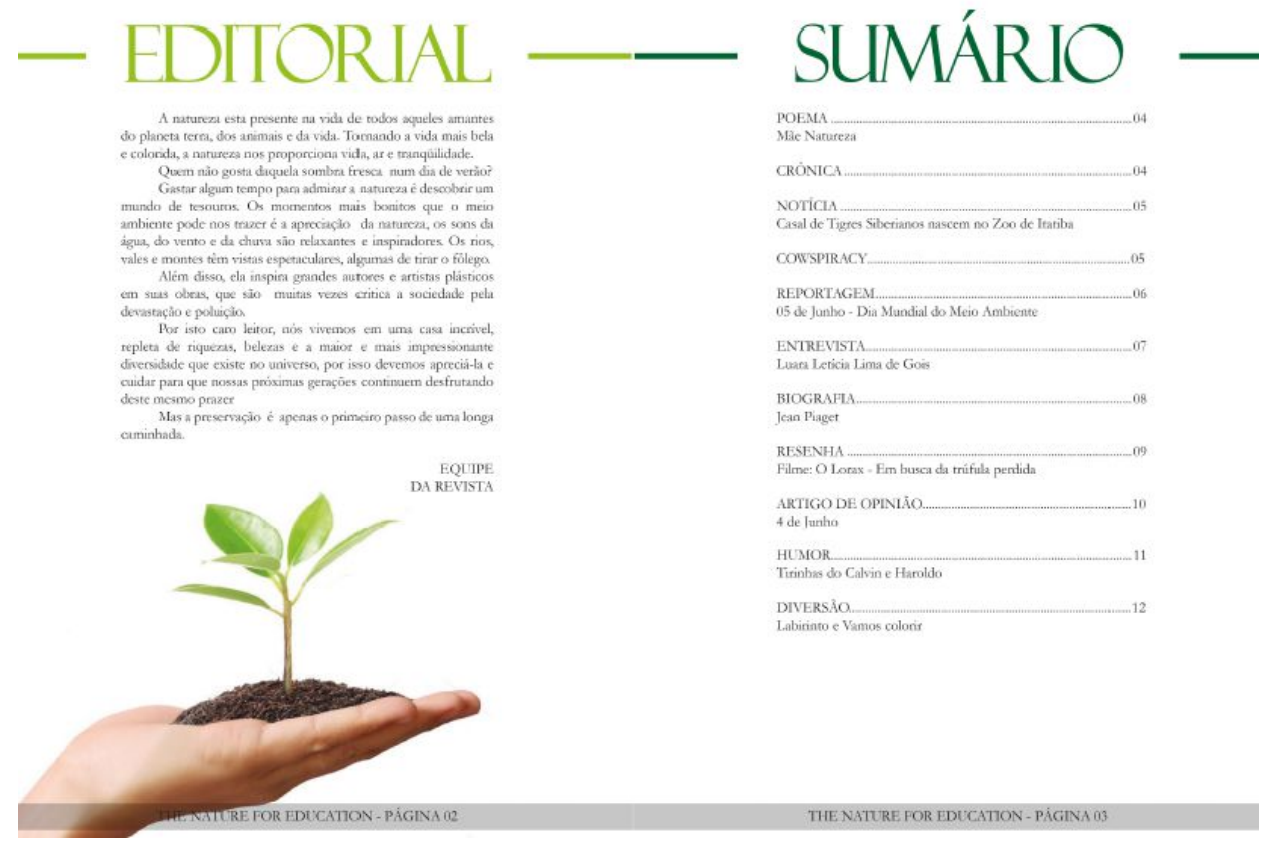

Fonte: arquivo das pesquisadoras

Nesse sentido, quando as estudantes dizem no editorial: "[...] caro leitor, nós vivemos em uma casa incrível, repleta de riquezas, belezas e a maior e mais impressionante diversidade que existe no universo, por isso, devemos apreciá-la e cuidar para que as próximas gerações continuem desfrutando deste mesmo prazer", são vários os interlocutores pressupostos: a professora universitária, os colegas de classe para quem o trabalho será apresentado, a comunidade acadêmica para a qual o trabalho será exposto etc. E, nesse sentido,

O papel dos outros, para quem se constrói o enunciado, é excepcionalmente grande, como já sabemos. Já dissemos que esses outros, para os quais o meu pensamento pela primeira vez se torna um pensamento real (e deste modo também para mim mesmo), não são ouvintes passivos mas participantes ativos da comunicação discursiva (BAKHTIN, 2010, p. 301).

As alunas assinam o editorial como Equipe da revista, uma vez que compreendem a função desse gênero textual: trazer a opinião do suporte jornalístico. Afinal, ele é um texto que 


\section{USF HоR IZONTES}

representa a posição do veículo de comunicação e não de um sujeito específico como ocorrem em artigos de opinião, por exemplo.

No sumário, conforme podemos visualizar na figura 2, podemos verificar que o grupo produziu diferentes gêneros textuais para a composição desse suporte: poema, crônica, notícia, anúncio (Cowspiracy), reportagem, entrevista, biografia, resenha, artigo de opinião, etc. Para compreender como se deu essa produção, analisemos uma delas.

Figura 3 - Gêneros que compuseram a revista

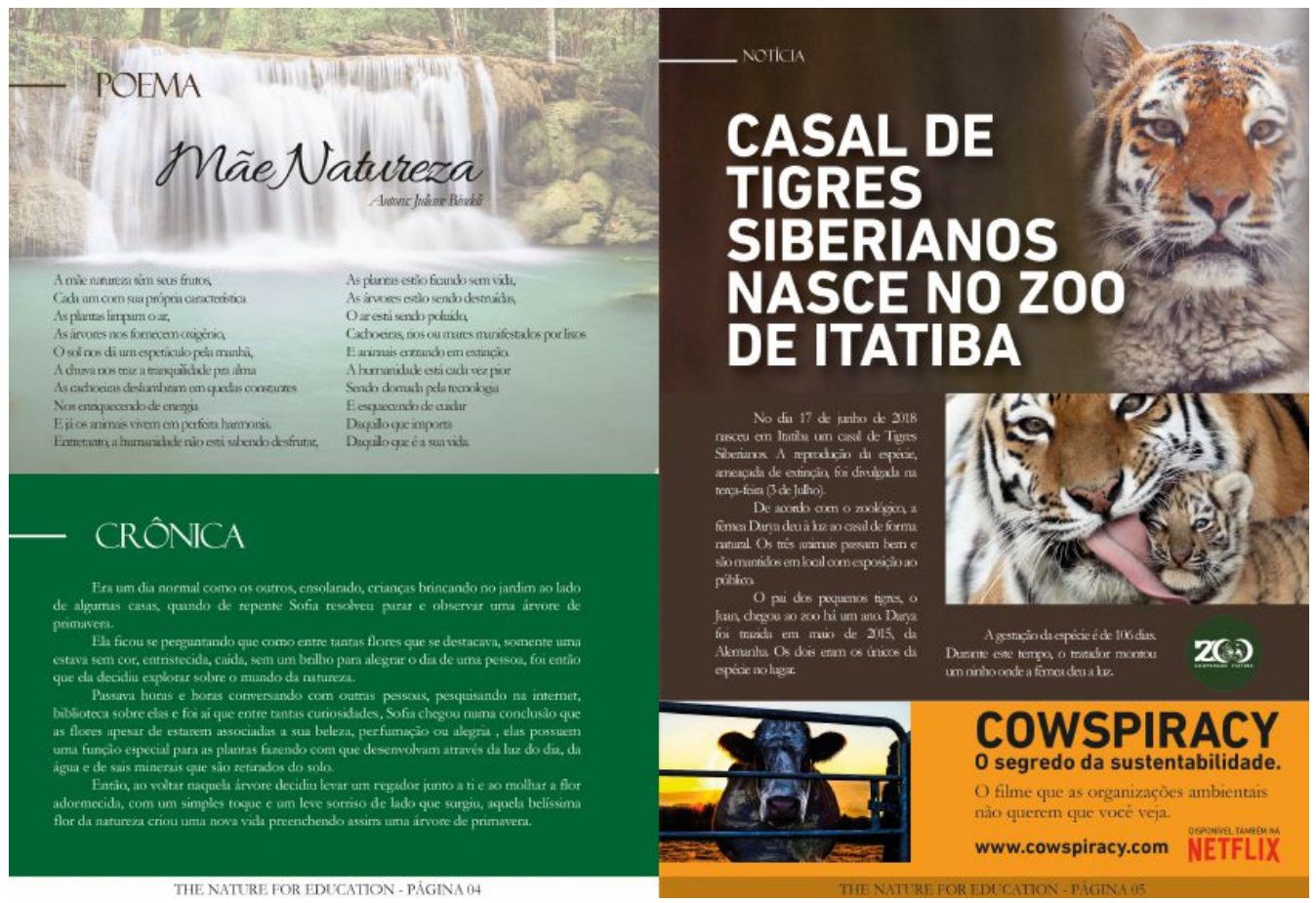

Fonte: arquivo das pesquisadoras

Ao analisar essa página da revista (Figura 3), vemos que ela é composta de quatro gêneros distintos: um poema, uma crônica, uma notícia e uma propaganda. Cada um desses gêneros apresenta um conteúdo temático, uma estrutura composicional e um estilo. Os textos produzidos visavam a interação verbal, práticas sociais de uso da linguagem e não a mera artificialidade de um trabalho escolar/acadêmico. Vejamos que na notícia, por exemplo, intitulada de "Casal de tigres siberianos nasce no zoo de Itatiba", as estudantes buscam informar ao público leitor (a professora, os colegas, a comunidade acadêmica) acerca de um acontecimento recente ocorrido no zoológico da cidade, na época da produção do editorial. 
Dão destaque ao título, colocam o verbo (nasce) no presente para tornar essa notícia mais recente, resumem o conteúdo da notícia - marca típica de manchetes de textos jornalísticos. Em seguida, no primeiro parágrafo do texto, trazem um lead que responde as seguintes perguntas: O que aconteceu? Quando aconteceu? Onde aconteceu? - característica do primeiro parágrafo de uma notícia:

No dia 17 de junho de 2018 nasceu em Itatiba um casal de Tigres Siberianos. A reprodução da espécie, ameaçada de extinção, foi divulgada na terça-feira (3 de julho).

Após a apresentação do lead, as estudantes dão seguimento ao texto apresentando um detalhamento do que fora informado no primeiro parágrafo:

De acordo com o zoológico, a fêmea Darya deu à luz ao casal de forma natural. Os três animais passam bem e são mantidos em local com exposição ao público.

O pai dos pequenos tigres, o Juan, chegou ao zoo há um ano. Darya foi trazida em maio de 2015, da Alemanha. Os dois eram os únicos da espécie no lugar.

A gestação da espécie é de 106 dias. Durante este tempo, o tratador montou um ninho onde a fêmea deu a luz.

Esse texto demonstra uma apropriação das características do gênero textual notícia: desde o contexto de produção do texto até os aspectos estruturais e linguísticos. As alunas reconhecem a função desse gênero textual: informar sobre um acontecimento local. Também reconhecem a estrutura desse gênero: como compor uma manchete, lead e o corpo da notícia. Utilizam, para isso, a linguagem formal, apesar de apresentarem pequenos desvios de linguagem. O conteúdo temático relaciona-se a um acontecimento de interesse para o público local.

Assim como nesse exemplo, essas alunas e os demais estudantes da turma foram transitando por variados gêneros discursivos das mais diversas esferas. Essa produção revelou um intenso movimento de escrita e reescrita, de produção coletiva. As revistas, além de apresentarem uma diversidade de gêneros que tinham função social, foram diagramadas assim 
como uma produção editorial. Ao final, o resultado foi: 10 revistas produzidas sobre diferentes assuntos temáticos, relacionados à área de educação, uma aprendizagem mediada pelo diálogo, pela coletividade e pelo outro.

Figura 4 - Produção editorial final apresentada pelos acadêmicos

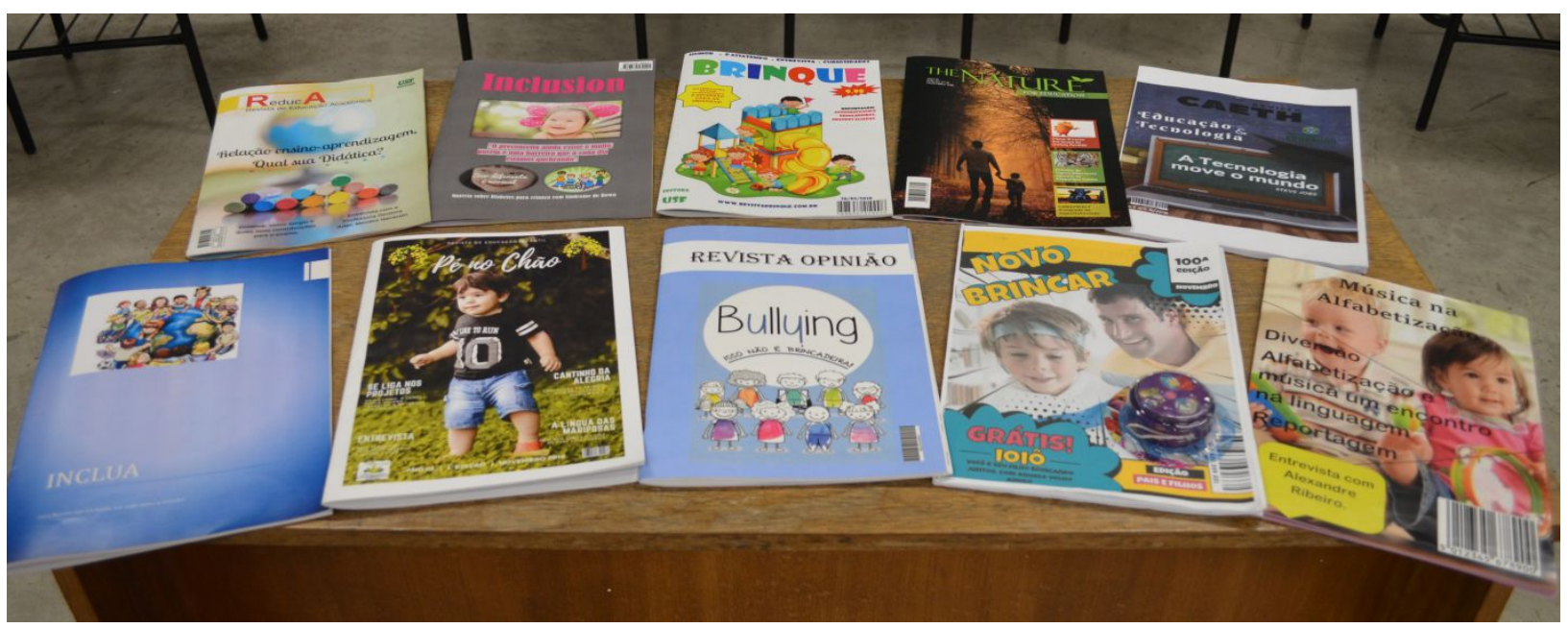

Fonte: arquivo das pesquisadoras

Ao ler as revistas produzidas, observamos que os alunos fizeram uso de diversos gêneros textuais que circulam nas mais diversas esferas da atividade humana. O Quadro 1 mostra quais gêneros foram utilizados pelos alunos para a construção do projeto editorial.

Quadro 1 - Gêneros produzidos no projeto editorial

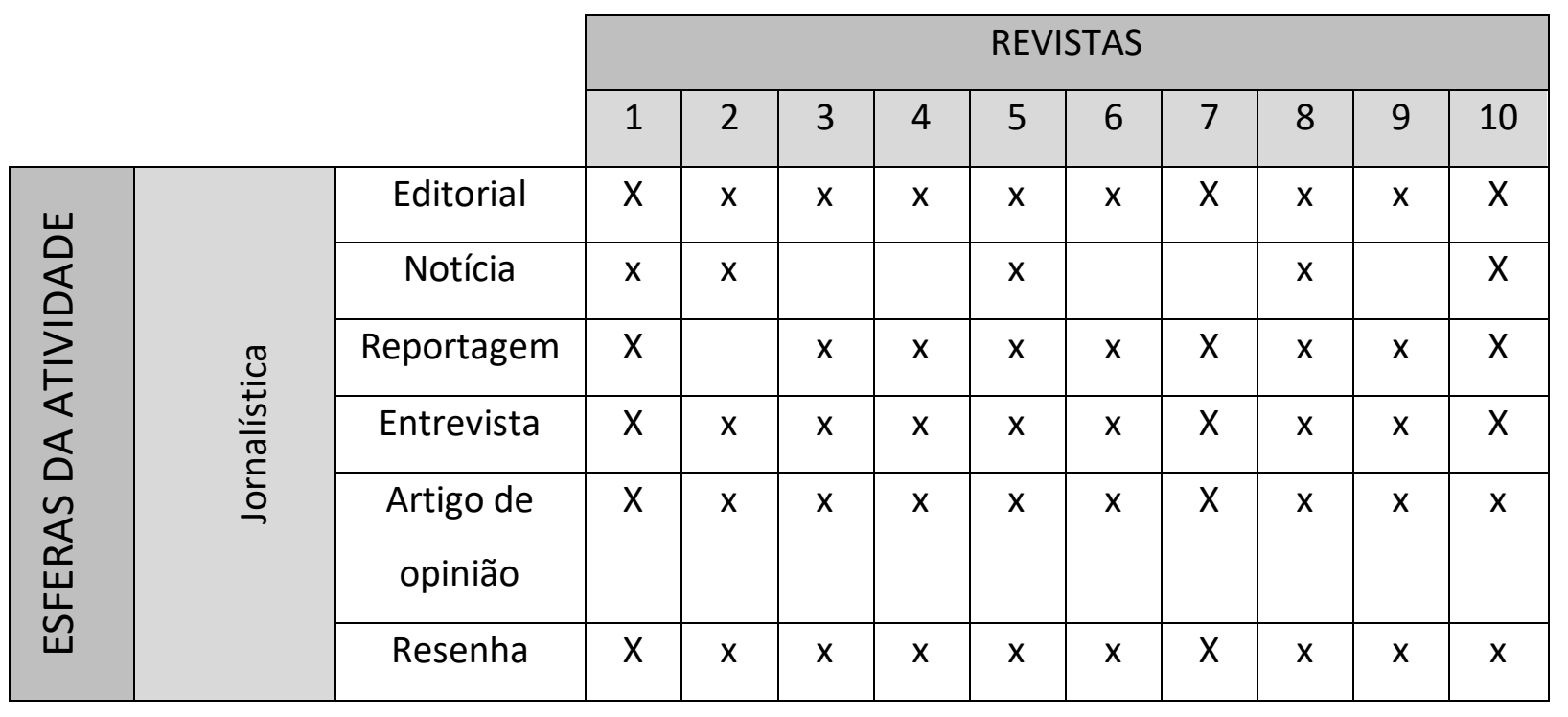

Periódico Horizontes - USF - Itatiba, SP - Brasil - e020010 


\begin{tabular}{|c|c|c|c|c|c|c|c|c|c|c|c|}
\hline \multirow{4}{*}{ 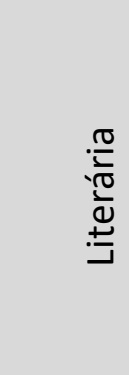 } & Poema & $X$ & $x$ & $x$ & & $x$ & $x$ & $X$ & $x$ & $x$ & $x$ \\
\hline & Crônica & $x$ & $x$ & $x$ & $\mathrm{X}$ & $x$ & $x$ & $X$ & $x$ & $x$ & $x$ \\
\hline & Tira & & & $x$ & $X$ & $x$ & $x$ & $X$ & $x$ & $x$ & $x$ \\
\hline & $\begin{array}{c}\text { (Auto) } \\
\text { Biografia }\end{array}$ & $\mathrm{x}$ & $x$ & $x$ & $\mathrm{X}$ & $x$ & $x$ & $X$ & $x$ & $x$ & $x$ \\
\hline \multirow{2}{*}{ 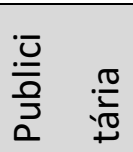 } & Propaganda & & $x$ & $x$ & $x$ & & $x$ & & $x$ & $x$ & $x$ \\
\hline & Anúncio & & & $x$ & $x$ & $x$ & $x$ & $x$ & $x$ & $x$ & $x$ \\
\hline
\end{tabular}

Fonte: Elaborado pelas pesquisadoras

O movimento de produção editorial, isto é, de produção dos gêneros das diferentes esferas, a reescrita desses textos e a diagramação foi permitindo aos sujeitos se apropriarem das especificidades de diversos gêneros que circulam por diferentes esferas. Esse movimento também contribuiu para que os futuros pedagogos fossem desenvolvendo o letramento profissional, uma vez que, como professores pedagogos que lecionam a língua materna, eles precisarão ensinar tais gêneros aos seus futuros alunos, de forma a possibilitar também a eles o letramento para agir nas mais diversas esferas da comunicação humana.

Assim, o texto torna-se mais do que meramente um objeto de ensino. O texto é condição sine qua non para que possamos agir nos diferentes campos da atividade humana. E, é somente a partir do trabalho com o texto, envolvendo práticas sociais efetivas de uso da linguagem que possibilitaremos ao outro se tornar letrado nas esferas em que esses gêneros circulam. Na escola, por exemplo, todos os gêneros aprendidos e apropriados pelos estudantes circulam como objetos de ensino. Assim, a experiência realizada no curso de Pedagogia com a revista traz indícios de um letramento profissional, à medida que ao se apropriar das especificidades de diversos gêneros, os futuros professores terão maiores condições de ensinálos e promover o letramento de seus alunos. 


\section{Considerações finais}

O objetivo deste texto consistiu em relatar e discutir acerca das contribuições de uma experiência prática de formação inicial, no que diz respeito à aprendizagem de leitura e escrita de gêneros textuais que - embora não pertençam à esfera acadêmica - serão objeto de ensino dos pedagogos em atuação em diferentes segmentos de ensino e anos em que irão atuar.

A proposta aqui descrita teve como base teórica os estudos dos Novos Letramentos, a partir da produção de uma revista cujo projeto editorial contemplou não apenas a apropriação de gêneros discursivos de diferentes esferas de circulação, mas também revelou existirem diferentes possibilidades de letramentos na formação inicial do pedagogo. A proposta se justifica em razão de esse profissional prescindir do domínio de gêneros discursivos com os quais trabalhará ao exercer sua profissão.

Essa variedade de gêneros e a complexidade de seu trabalho estão atreladas a currículos que norteiam a atividade docente do pedagogo. Assim, o professor atuante no ensino fundamental 1, ao ministrar a disciplina de língua portuguesa, por exemplo, vê-se diante de um contexto em que deverá mobilizar conhecimentos cada vez mais peculiares, haja vista que as práticas de letramentos realizadas com os alunos centram-se no trabalho com gêneros discursivos de diferentes esferas da atividade humana.

Ao possibilitar contato, análise, leitura e produção de gêneros diversos, os sujeitos envolvidos neste estudo - acadêmicos do 5. semestre do curso de Pedagogia - puderam se apropriar das peculiaridades de cada gênero discursivo em foco, além de recorrer a conhecimentos sobre a esfera de circulação a que pertencem. Assim, os conhecimentos necessários aos textos produzidos em relação às práticas de leitura e escrita puderam ser, antes de se tornarem objetos de ensino dos futuros professores pedagogos, apropriados e praticados por eles. 


\section{Referências}

BAKHTIN, M. Os gêneros do discurso. In: BAKHTIN, M. A estética da criação verbal. Tradução de Paulo Bezerra. 5.ed. São Paulo: Martins Fontes, 2010, p.261-306.

BRASIL, [BNCC (2018)]. Base Nacional Comum Curricular: educação é a base. Brasília, DF: Presidência da República, 2018. Disponível em: www.basenacionalcomum.mec.gov.br. Acesso em: 30. 09.2019.

BRASIL [PCN (1999)]. Parâmetros Curriculares Nacionais: língua portuguesa. Brasília, DF: Presidência da República, 1999. Disponível em http://portal.mec.gov.br/seb/arquivos/pdf/livro02.pdf. Acesso em: 30. 09.2019.

COLAÇO, S. F. Práticas pedagógicas de letramento: uma visão ideológica. In: IX ANPED SUL. SEMINÁRIOS DE PESQUISA NA REGIÃO SUL. ANAIS da IX ANPEDSUL. Caxias do Sul: UCS, 2012. Disponível em:

http://www.ucs.br/etc/conferencias/index.php/anpedsul/9anpedsul/paper/viewFile/2148/589 Acesso em 30.09.2019.

COSTA, K. R. da; PAZ, A. M. de O. Letramento profissional: estudos em perspectivas. Revista do GELNE. Natal/RN, Vol. 19 - Número Especial: p. 199-209, 2017. Disponível em:

https://periodicos.ufrn.br/gelne/article/view/12592/9207. Acesso em 28.09.2019.

KLEIMAN, A. Letramento na contemporaneidade. Bakhtiniana: Rev. Estud. Discurso. São Paulo, v.9, n.2, jul-dez, 2014. Disponível em:

http://www.scielo.br/scielo.php?script=sci arttext\&pid=S2176-45732014000200006. Acesso em 28.09.2019.

KLEIMAN, A. Os significados do letramento: uma nova perspectiva sobre a prática social da escrita. 1. ed. Campinas: Mercado da Letras, 1995.

MARCUSCHI, L. A. Gêneros textuais: definição e funcionalidade. In: DIONISIO, A.P.; MACHADO, A. R.; BEZERRA, M. A. Gêneros Textuais e Ensino. Rio de Janeiro: Lucerna, 2010, p. 19-38.

ROJO, R. Letramentos múltiplos, escola e inclusão social. 1. ed. São Paulo: Parábola Editorial, 2009.

ROJO, R. CEALE. Termos de Alfabetização, Leitura e Escrita para Educadores. Universidade Federal de Minas Gerais (UFMG). Disponível em:

http://ceale.fae.ufmg.br/app/webroot/glossarioceale/verbetes/esferas-ou-campos-deatividade-humana. Acesso em 30.09.2019.

ROJO, R.; BARBOSA, J. Hipermodernidade, multiletramentos e gêneros discursivos. 1.ed. São Paulo: Parábola Editorial, 2015. 
SCHNEUWLY, B.; DOLZ, J. Gêneros orais e escritos na escola. [Tradução e organização: Roxane Rojo e Glaís Sales Cordeiro]. Campinas-SP: Mercado de Letras, 2004.

STREET, B. V. Letramentos sociais: abordagens críticas do letramento no desenvolvimento, na etnografia e na educação. Tradução de Marcos Bagno. São Paulo: Parábola Editorial, 2014.

Recebido em setembro 2019.

Aprovado em dezembro 2019. 